\title{
Color preference as a function of the object described
}

\author{
COOPER B. HOLMES and JO ANN BUCHANAN \\ Emporia State University, Emporia, Kansas
}

(Stephen F. Davis, sponsor)

\begin{abstract}
Noting the inconsistent research on the relationship between color and personality, the authors present data on one of the possible reasons for the problem. The problem addressed is that color/personality research almost always presents a color patch or patches and draws inferences from the subjects' choices, ignoring the possibility that color preference is related to the object in question. College students were asked to give their favorite colors for a number of items (e.g., automobile). The results clearly show that color preference is a function of the object described. That is, color preference cannot be asked independently of an object if that color preference is to have interpretive significance.
\end{abstract}

The possibility of color preference revealing personality traits and emotions is a popular idea dating to antiquity and having no less an adherent than Goethe (Frank, 1976) and no less a researcher than Eysenck (1941). A color/personality relationship is virtually unquestioned in areas such as interior design, art therapy, and projective testing (Luscher \& Scott, 1969). Yet, when controlled research is conducted, the findings are inconsistent, and the color/personality relationship appears weak, at best. Although a complete review of the literature on this topic is not necessary, several studies must be noted because of their direct applicability to the present paper.

Luscher and Scott (1969) cited nearly 150 articles supporting the color/personality relationship as reflected through the Luscher Color Test (LCT). Unfortunately, these studies are not readily available to American psychology, because the articles are in foreign journals. Birren (1978) also cited numerous studies in support of such a relationship. Adels (1978), with children as subjects, French and Alexander (1972), using college students, and Rahn (1976), using criminals and civilians, all found evidence in favor of the color/personality relationship (using colors of the LCT). On the other hand, a review of the literature on the possiblity of a color/ personality relationship failed to indicate support for such an idea (Cerbus \& Nichols, 1963). Marzolf and Kirchner (1973) studied color use with the house-treeperson test and concluded that color choice offered only a tentative suggestion of personality traits. Frank(1976), in a comprehensive review of color studies, also came to the same basic conclusion as Marzolf and Kirchner.

Requests for reprints should be sent to Cooper B. Holmes, Department of Psychology, Emporia State University, Emporia, KS 66801 .
Clearly, the empirical support for a color/personality relationship is lacking; at best, it is confusing and inconsistent. One possible reason, among many, for this problem is that past research has failed to take into account the possibility that color choice is not independent of specific objects (e.g., an automobile).

Although it may seem rather obvious that color choice or preference is related to the object in question, writers in the field do not agree on the point. Sharpe (1974) categorically stated that color preference, as well as many other variables, such as gender, is related to objects. Birren (1978) refuted the idea of color preference's being determined by objects; he preferred to have subjects make what he called "innate choices of the heart." Luscher (Luscher \& Scott, 1969) oddly noted that color may be related to specific objects, but went on to state that, in responding to his LCT colors, the subject must set aside these possibilities while making an "instinctual" choice. Virtually all the research on the relationship between color and personality has followed the Birren and Luscher idea of having subjects make color choices independent of any object. From these choices, the researchers make inferences about personality and emotional traits. To the present authors, color preference in a forced-choice or limited-choice situation seems specious and arbitrary in itself, but to go further and relate these choices to personality variables is even less defensible. The present study was designed to examine how color preference relates to the object in question. These results of course bear directly on the color/ personality relationship research.

\section{METHOD}

\section{Subjects}

Fifty-eight female and 31 male students enrolled in introductory psychology classes completed a form indicating various color preferences. All subjects were volunteers. 


\section{Instrument}

Each subject was given a sheet of paper on which appeared the instructions (see below) and nine blank spaces in which the subject wrote his or her response. For females, the spaces were preceded by the words "Overall Favorite Color," "Automobile," "Blouse," "Skirt," "Dress," "Carpet," "Sofa," "Chair," and "Walls." For males, the spaces were preceded by the words "Overall Favorite Color," "Automobile," "Shirt," "Slacks," "Suit," "Carpet," "Sofa," "Chair," and "Walls."

The instructions were as follows, with the appropriate genderrelated word injected here in parentheses (only the appropriate gender word appeared in the actual instructions):

In the blank spaces below, please give the name of the color you personally prefer for each of the items. You do not have to use the same color for all items, although you may if that is your true preference. Please give only one color per item. If you prefer, for example, a plaid, give the dominant color. Do these separately (do not try to coordinate, for example, blouse [ shirt] color with skirt [suit] color).

\section{Procedure}

The previously described forms were handed out in class and were completed within a few minutes. The only instructions were those on the form itself.

\section{RESULTS}

In compiling these data, we faced a dilemma in that we were tempted to present the complete list of colors used (for females, this would have been 45) but at the same time realized that a table presenting all these data would be probably unnecessarily lengthy. In many cases, a color was used only once. In the interest of clarity and brevity, we have combined all the similar colors, but we have listed all the names used by the subjects for that color group. We feel it is important to present all the names in order to show the rich variety of colors used and the number of times the subjects felt it necessary to qualify a color by calling it "dark," "light," "dusty," or some other adjective. Table 1 presents the results for females. Table 2 presents the results for males.

We must note that no formal statistical analysis was performed on these data, because none was necessary. That is, we did not set out to prove any specific hypotheses; rather, we set out to describe the color preferences of our subjects.

\section{DISCUSSION}

These results present a number of areas that require discussion. First, we must note that our results do not agree with those of several other studies with respect to the overall favorite color choice. Luscher (Luscher \& Scott, 1969) found red to be the preferred color among European males, Donnelley (1974) found yellow to be the favorite of both male and female college students, Braun and Bonta (1979) found Canadian males to prefer red, Birren (1978) noted red and blue to be preferred, and Rahn (1976) found blue to be the first choice of civilians and criminals. The present results clearly showed blue to be the favorite overall color for males and females.

Second, there is a blatant difference between what subjects

Table 1

Number of Times Females Indicated Color Preference for Various Objects

\begin{tabular}{|c|c|c|c|c|c|c|c|c|c|}
\hline Colors & $\begin{array}{c}\text { Overall } \\
\text { Favorite }\end{array}$ & $\begin{array}{l}\text { Auto- } \\
\text { mobile }\end{array}$ & Blouse & Skirt & Dress & Carpet & Sofa & Chair & Walls \\
\hline $\begin{array}{l}\text { Blue, Dark Blue, } \\
\text { Navy Blue }\end{array}$ & 25 & 13 & 9 & 19 & 14 & 3 & 5 & 3 & 9 \\
\hline $\begin{array}{l}\text { Light Blue, Baby Blue, } \\
\text { Dusty Blue }\end{array}$ & 2 & 2 & 0 & 0 & 4 & 1 & 0 & 0 & 1 \\
\hline $\begin{array}{l}\text { Brown, Dark Brown, } \\
\text { Deep Brown, Cocoa }\end{array}$ & 0 & 2 & 1 & 7 & 1 & 15 & 19 & 28 & 4 \\
\hline $\begin{array}{l}\text { Light Brown, Tan, } \\
\text { Beige, Khaki }\end{array}$ & 0 & 0 & 0 & 1 & 2 & 4 & 10 & 7 & 10 \\
\hline $\begin{array}{l}\text { White, Off White, } \\
\text { Ivory, Cream }\end{array}$ & 1 & 2 & 6 & 1 & 3 & 1 & 2 & 3 & 22 \\
\hline Pink & 4 & 0 & 6 & 0 & 4 & 2 & 2 & 1 & 0 \\
\hline $\begin{array}{l}\text { Lavender, Violet, } \\
\text { Mauve }\end{array}$ & 3 & 0 & 7 & 1 & 3 & 1 & 0 & 0 & 0 \\
\hline $\begin{array}{l}\text { Purple, Dark Purple, } \\
\text { Plum }\end{array}$ & 6 & 0 & 3 & 2 & 5 & 0 & 0 & 0 & 0 \\
\hline $\begin{array}{l}\text { Red, Rust, } \\
\text { Burgundy, Maroon }\end{array}$ & 1 & 13 & 10 & 3 & 5 & 0 & 1 & 0 & 0 \\
\hline Yellow, Bright Yellow & 2 & 0 & 3 & 0 & 2 & 1 & 1 & 0 & 4 \\
\hline Green, Dark Green & 2 & 0 & 2 & 1 & 0 & 2 & 0 & 3 & 0 \\
\hline $\begin{array}{l}\text { Orange, Burnt Orange, } \\
\text { Amber }\end{array}$ & 2 & 0 & 0 & 0 & 1 & 2 & 2 & 1 & 1 \\
\hline Peach, Apricot & 0 & 0 & 3 & 0 & 0 & 0 & 0 & 0 & 0 \\
\hline Turquoise, Aqua & 4 & 0 & 1 & 0 & 1 & 0 & 0 & 0 & 0 \\
\hline Gray & 0 & 3 & 0 & 9 & 1 & 1 & 0 & 0 & 0 \\
\hline Silver & 0 & 7 & 0 & 0 & 0 & 0 & 0 & 0 & 0 \\
\hline Black & 0 & 9 & 1 & 7 & 4 & 0 & 1 & 0 & 0 \\
\hline Gold & 0 & 0 & 0 & 0 & 0 & 3 & 5 & 4 & 1 \\
\hline
\end{tabular}


Table 2

Number of Times Males Indicated Color Preference for Various Objects

\begin{tabular}{|c|c|c|c|c|c|c|c|c|c|}
\hline Colors & $\begin{array}{l}\text { Overall } \\
\text { Favorite }\end{array}$ & $\begin{array}{l}\text { Auto- } \\
\text { mobile }\end{array}$ & Shirt & Slacks & Suit & Carpet & Sofa & Chair & Walls \\
\hline $\begin{array}{l}\text { Blue, Dark Blue, } \\
\text { Navy Blue }\end{array}$ & 22 & 7 & 14 & 14 & 7 & 4 & 1 & 0 & 2 \\
\hline Light Blue, Sky Blue & 1 & 1 & 0 & 1 & 3 & 0 & 1 & 0 & 3 \\
\hline $\begin{array}{l}\text { Brown, Dark Brown, } \\
\text { Light Brown, Beige, } \\
\text { Tan, Camel }\end{array}$ & 0 & 1 & 2 & 2 & 7 & 6 & 5 & 1 & 2 \\
\hline $\begin{array}{l}\text { White, Off White, } \\
\text { Cream }\end{array}$ & 1 & 0 & 4 & 2 & 0 & 1 & 3 & 1 & 14 \\
\hline $\begin{array}{l}\text { Red, Rust, } \\
\text { Maroon, Candy Red }\end{array}$ & 3 & 8 & 1 & 0 & 0 & 2 & 2 & 2 & 0 \\
\hline Yellow & 1 & 1 & 4 & 0 & 0 & 0 & 1 & 2 & 1 \\
\hline Green & 1 & 2 & 1 & 0 & 1 & 1 & 0 & 0 & 1 \\
\hline Burnt Orange & 0 & 0 & 0 & 0 & 0 & 0 & 0 & 1 & 0 \\
\hline Gray & 1 & 3 & 0 & 4 & 7 & 0 & 0 & 0 & 0 \\
\hline Silver & 0 & 3 & 0 & 0 & 1 & 0 & 0 & 0 & 0 \\
\hline Black & 1 & 3 & 1 & 3 & 1 & 0 & 2 & 1 & 0 \\
\hline Gold & 0 & 0 & 0 & 0 & 0 & 1 & 1 & 1 & 0 \\
\hline Woodgrain & 0 & 0 & 0 & 0 & 0 & 0 & 0 & 1 & 1 \\
\hline
\end{tabular}

indicate to be their favorite overall color and the colors they pick for given objects. Specifically, no male or female picked brown to be their favorite color, but, as Tables 1 and 2 show, brown was picked slightly more of ten for both sexes as the color choice for most of the items (combining the dark and the light browns). Over all possibilities, females picked brown 111 times (to 110 for blue), and males picked brown 98 times (to 91 for blue). Clearly, there is a discrepancy when blue is picked as the favorite overall color, but brown is given as often as blue. It seems reasonable to assume that one's favorite color would be picked for a variety of objects. It was not so in this study.

Third, we cannot help but note the remarkable variety of colors noted both as favorite overall color and as favorite colors for various objects. Females required 45 colors to describe the various objects, and males required 26 selections. Broken down further than in Tables 1 and 2 , the data show that females required 15 colors to describe their overall favorite and that males required 9 to do so.

Fourth, stereotypes about color preference were supported by these data. That is, whereas female subjects picked pink or lavender shades as favorite seven times and used them 27 times to describe various objects, these colors were not noted at all by males.

By this time, it is apparent that the present authors are avoiding any interpretation of why colors were or were not selected. This is quite intentional, because such an endeavor would lead far afield from the intent of this paper. This research was designed to examine the relationship between color choice and specific objects, not why a given color was or was not preferred.

The results consistently indicate that color preference as a personality indicator is questionable. The present data (as well as those of other studies previously mentioned) show gender differences, regional differences, gross inconsistencies across studies, and clear inconsistencies between favorite color choices for various objects. We assert that it is simplistic-and, frankly, inaccurate-to give a subject a color patch (or patches) in a forced-choice or limited-choice situation and then make inferences about personality from that contrived situation. It is not surprising that the research on color and personality is incon- sistent and confusing. There is little reason to expect a clearer picture until research becomes much more sophisticated.

\section{REFERENCES}

Adels, J. (1978). An assessment of Luscher's Eight Color Test as a screening instrument for emotional disturbance in school children. Dissertation Abstracts International, 39, 967B-968B.

Birren, F. (1978). Color in your world. New York: Collier.

Braun, C., \& Bonta, J. (1979). Cross-cultural validity, reliability and stimulus characteristics of the Luscher Color Test. Journal of Personality Assessment, 43, 459-460.

Cerbus, G., \& Nichols, R. (1963). Personality variables and response to color. Psychological Bulletin, 60, 566-575.

Donnelley, F. (1974). The Luscher Color Test: Reliability and selection preferences by college students. Psychological Reports, 34, 635-638.

Eysenck, H. (1941). A critical empirical study of color preferences. American Journal of Psychology, 54, 358.

Frank, G. (1976). On the validity of hypotheses derived from the Rorschach: I. The relationship between color and affect. Perceptual and Motor Skills, 43, 411-427.

French, C., \& Alexander, B. (1972). The Luscher Color Test: An investigation of validity and underlying assumptions. Journal of Personality Assessment, 36, 361-365.

Luscher, M., \& ScotT, I. (1969). The Luscher Color Test. New York: Random House.

Marzolf, S., \& Kirchner, J. (1973). Personality traits and color choices for HTP drawings. Journal of Clinical Psychology, 29, 240-245.

RAHN, R. (1976). Luscher color theory: Civilians and criminals. Art Psychotherapy, 3, 145-155.

Sharpe, D. (1974). The psychology of color and design. Chicago: Nelson-Hall.

(Manuscript received for publication March 21, 1984.) 